\title{
N-Butylpyridinium undecachlorocarbadodecaborate and comparison with similar compounds
}

\author{
Sebastian A. Suarez, Ana Foi, Shawn Eady, Anna Larsen and Fabio \\ Doctorovich
}

Acta Cryst. (2011). C67, o417-0420

Copyright (C) International Union of Crystallography

Author(s) of this paper may load this reprint on their own web site or institutional repository provided that this cover page is retained. Republication of this article or its storage in electronic databases other than as specified above is not permitted without prior permission in writing from the IUCr.

For further information see http://journals.iucr.org/services/authorrights.html

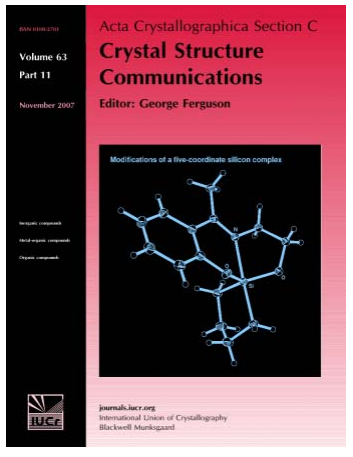

Acta Crystallographica Section C: Crystal Structure Communications specializes in the rapid dissemination of high-quality studies of crystal and molecular structures of interest in fields such as chemistry, biochemistry, mineralogy, pharmacology, physics and materials science. The numerical and text descriptions of each structure are submitted to the journal electronically as a Crystallographic Information File (CIF) and are checked and typeset automatically prior to peer review. The journal is well known for its high standards of structural reliability and presentation. Section $C$ publishes approximately 1000 structures per year; readers have access to an archive that includes high-quality structural data for over 10000 compounds.

Crystallography Journals Online is available from journals.iucr.org 
Acta Crystallographica Section C

Crystal Structure

Communications

ISSN 0108-2701

\section{N-Butylpyridinium undecachloro- carbadodecaborate and comparison with similar compounds}

\author{
Sebastian A. Suarez, ${ }^{\text {a }}$ Ana Foi, ${ }^{\text {a Shawn Eady, }}$, Anna \\ Larsen $^{\mathrm{b}}$ and Fabio Doctorovich ${ }^{\mathrm{a} *}$
}

aDepartamento de Química Inorgánica, Analítica y Química Física/INQUIMAECONICET, Facultad de Ciencias Exactas y Naturales, Universidad de Buenos Aires, Argentina, and ${ }^{\mathbf{b}}$ Department of Chemistry, Ithaca College, 953 Danby Road, Ithaca, NY 14850, USA

Correspondence e-mail: doctorovich@qi.fcen.uba.ar

Received 21 July 2011

Accepted 29 August 2011

Online 29 September 2011

The title compound, $\mathrm{C}_{9} \mathrm{H}_{14} \mathrm{~N}^{+} \cdot \mathrm{CHB}_{11} \mathrm{Cl}_{11}{ }^{-}$, was obtained in the course of our continuing studies of the low-melting salts of closo- and nido-carborane cage anions with alkylpyridinium and dialkylimidazolium cations. The title compound is the first example of a pyridinium salt of a perchlorinated carborane anion. The structure consists of one $N$-butylpyridinium cation counterbalanced by one perchlorinated carborane cage anion per asymmetric unit. By changing the counter-ion, different packings are observed, and to try to understand this the new structure is compared with five similar compounds.

\section{Comment}

In the last decade, the low-melting salts of the family of the title compound, $N$-butylpyridinium undecachlorocarbadodecaborate, (I), have been studied (Larsen et al., 2000; Dymon et al., 2008; Reed, 2010). Recently, the perchlorinated carborane species became available due to the work of Ozerov and co-workers (Gu et al., 2010). Compound (I) is the first example of a pyridinium salt of a perchlorinated carborane anion. The general synthetic route to obtain such compounds involves metathesis of an alkylpyridinium halide with caesium carborane salts in dichloromethane, with concominent precipitation of the caesium halide by-product (for more details, see Experimental).

The structure of carborane (I) consists of one butylpyridinium cation counterbalanced by an undecachlorinated carborane cage anion per asymmetric unit (Fig. 1). Structural analysis of the cation shows no significant differences from a typical substituted pyridine. The larger displacement ellipsoid observed for atom $\mathrm{C} 1$ is due to thermal movement of this terminal $\mathrm{C}$ atom of the alkyl chain. Thermal motion of atom $\mathrm{C} 1$ makes the $\mathrm{C} 1-\mathrm{C} 2$ bond appear to be shorter than a typical $\mathrm{C}-\mathrm{C}$ distance $[\mathrm{C} 1-\mathrm{C} 2=1.408(15) \AA]$. In the anion, all the
$\mathrm{B}-\mathrm{B}$ and $\mathrm{B}-\mathrm{Cl}$ distances are $\sim 1.8 \AA$ and the different torsion angles (near $0^{\circ}$ ) are within the expected ranges for undecachlorocarbadodecaborate.
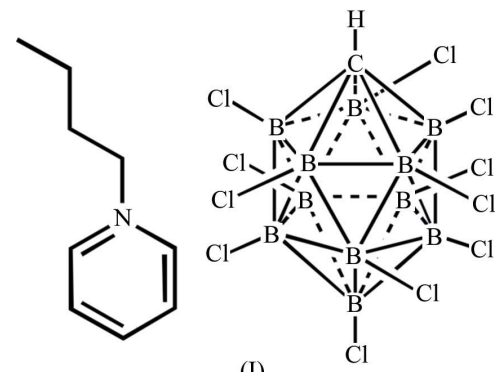

(I)

An intermolecular analysis shows that atom $\mathrm{Cl} 8$ in the undecachlorinated carborane interacts through a halogen $-\pi$ interaction with the $N$-butylpyridinium cation $[\mathrm{B} 8-\mathrm{Cl} 8 \rightarrow$ $C g 1=3.768$ (4) $\AA$; $C g 1$ is the centroid of the pyridine ring] (halogen bonding is a highly directional interaction, more directional than hydrogen bonding and comparable in strength; Metrangolo et al., 2008). It is important to point out that there is no evidence of strong $\pi-\pi$ interactions between the $N$-butylpyridinium rings, so we can presume that the driving force for the crystal packing is related to the hydrogenbond interaction $\mathrm{H} 10 \cdots \mathrm{Cl} 2^{\mathrm{i}}$ [2.94 (5) $\mathrm{A}$; symmetry code: (i) $-x+1,-y+1,-z+1]$ between undecachlorinated carboranes (see Fig. 2) (van den Berg \& Seddon, 2003; Lu et al., 2007). It is interesting to note the short $\mathrm{Cl} 1 \cdots \mathrm{Cl} 1^{\text {ii }}$ distance of 3.410 (3) $\AA$ [symmetry code: (ii) $-x+1, y,-z+\frac{1}{2}$ ], suggesting an interaction between these atoms, in addition to the short $\mathrm{H} \cdot \mathrm{Cl}$ cation-anion distances [minimum distance: $\mathrm{H} 1 B \cdots \mathrm{Cl} 2^{\mathrm{iii}}=2.8838$ (15) $\AA$; symmetry code: (iii) $x,-y, z-\frac{1}{2}$ ].

A supramolecular analysis shows that the most relevant and strongest intermolecular interactions in this structure are

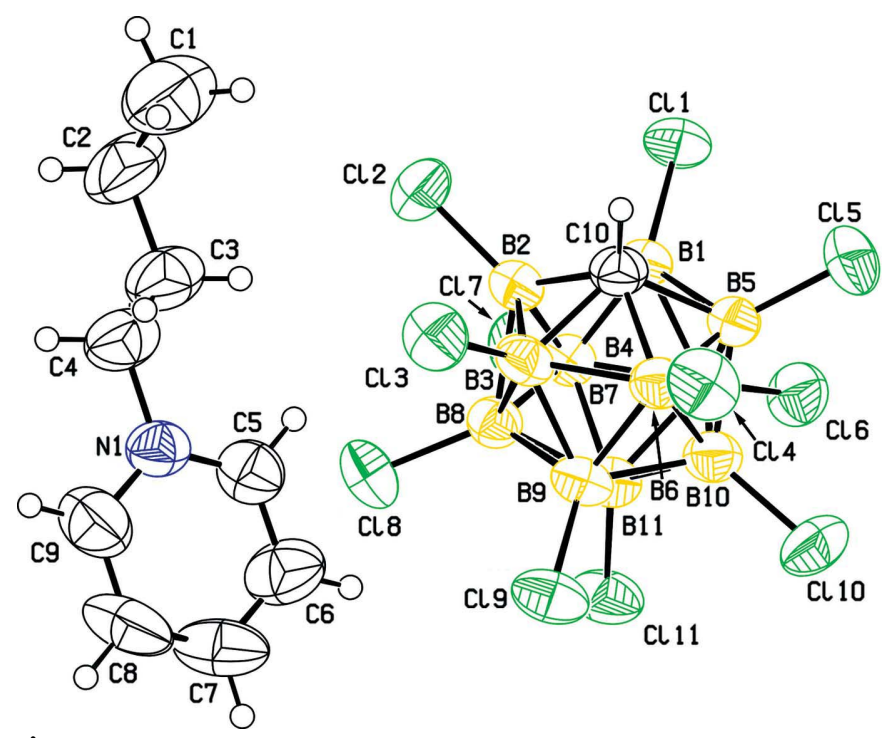

Figure 1

The molecular conformation and atom-numbering scheme for (I). Displacement ellipsoids are drawn at the $50 \%$ probability level. 


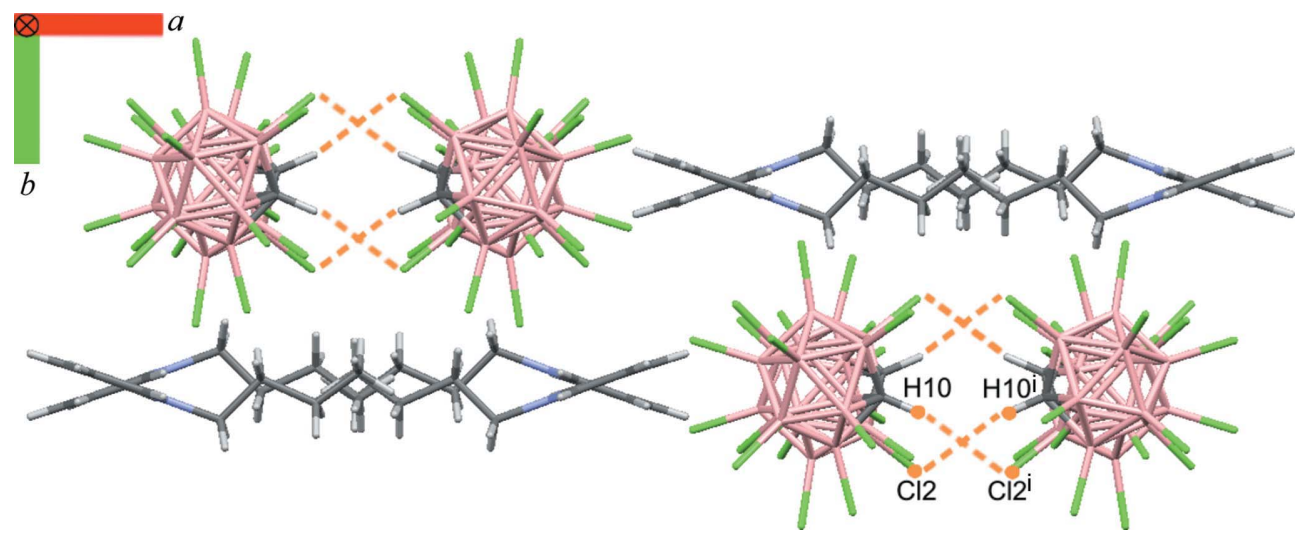

Figure 2

The $\mathrm{H} \cdots \mathrm{Cl}$ interactions (dotted lines) in the crystal packing of (I). [Symmetry code: (i) $-x+1,-y+1,-z+1$.]

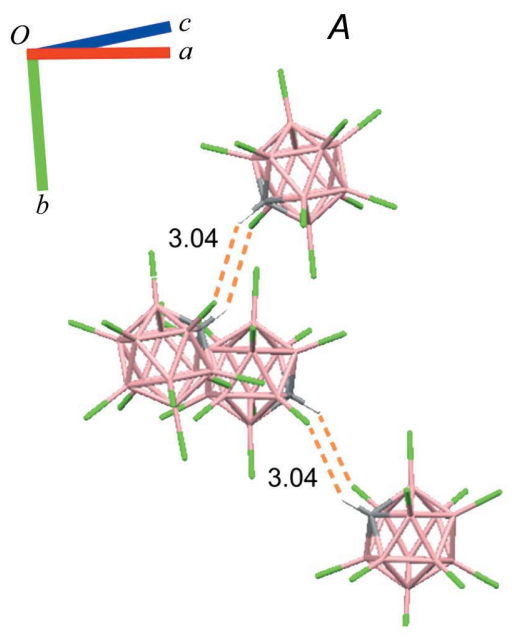

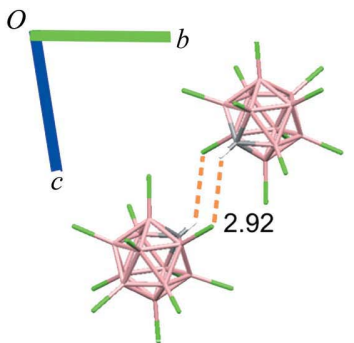
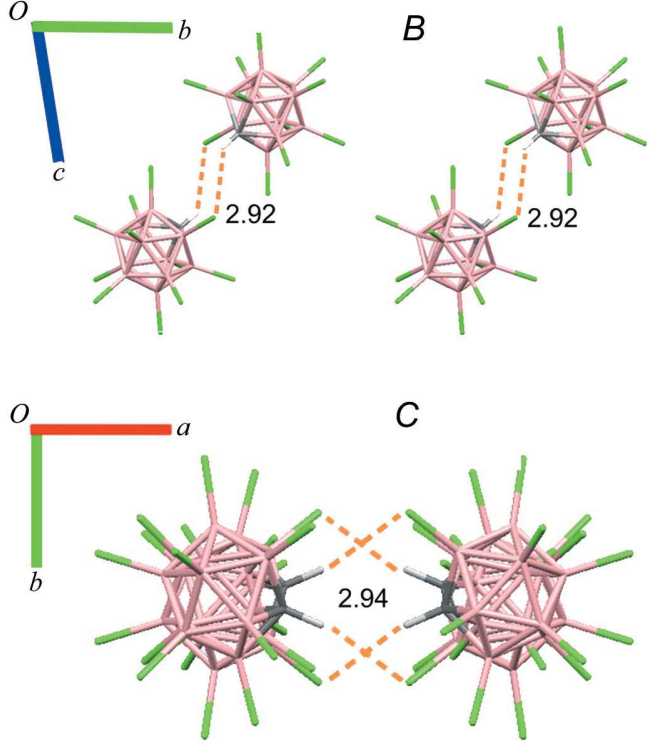
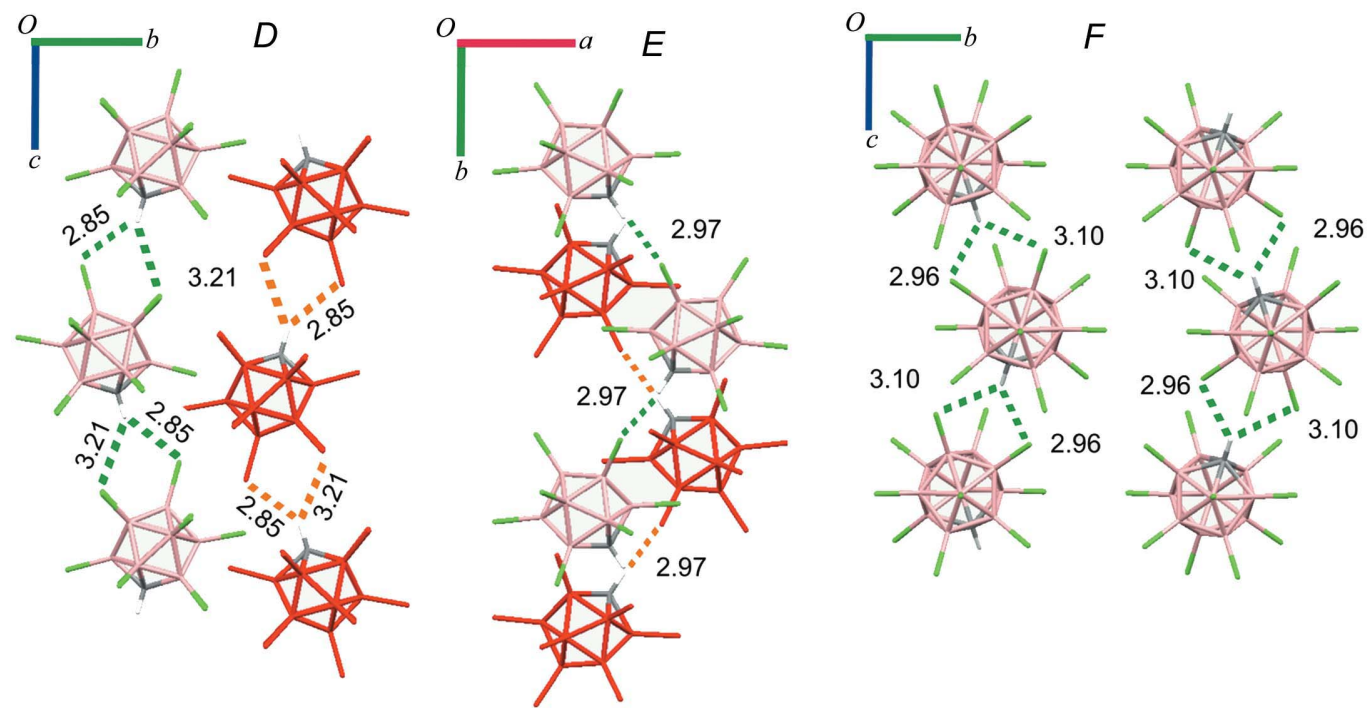

Figure 3

The packing arrangements for undecachlorocarbadodecaborate with different counter-ions. $A, B$ and $C$ are larger counter-ions, and $D, E$ and $F$ are smaller counter-ions, where $A$ is $\mathrm{Me}_{3}-\mathrm{Si}-\mathrm{H}-\mathrm{Si}-\mathrm{Me}_{3}$ (Hoffmann et al., 2006), $B$ is $N$-butylpyridinium (this work), $C$ is $\left(\mathrm{C}_{3} \mathrm{H}_{7}\right)_{3}-\mathrm{Si}-(\mathrm{ODCB})(\mathrm{ODCB}$ is $o$-dichlorobenzene; Hoffmann et al., 2006), $D$ is Me-Cl-Me (Stoyanov et al., 2010), $E$ is Et-Cl-Et (Stoyanov et al., 2010) and $F$ is $\left[\mathrm{H}(\mathrm{MeOH})_{3}\right]^{+}(\mathrm{Stoyanov}$ et al., 2008). Distances are given in $\AA$.

0418 Suarez et al. $\cdot \mathrm{C}_{9} \mathrm{H}_{14} \mathrm{~N}^{+} \cdot \mathrm{CHB}_{11} \mathrm{Cl}_{11}{ }^{-}$ 
clearly the already-mentioned hydrogen bonds. A dimer-like anionic substructure can be described as a result of the abovementioned contacts (Fig. 2). An adequate expansion allows the visualization of the infinite columnar arrangement built by these dimeric units, where the alternating positions of the carborane are evidenced by the torsion angle between subsequent units $\left[\mathrm{C} 10 \cdots C e \cdot C e^{\mathrm{iv}} \cdots \mathrm{C} 10^{\mathrm{iv}}=32.91^{\circ} ; \mathrm{Ce}\right.$ is the centroid of the undecachlorocarbadodecaborate cage; symmetry code: (iv) $x,-y+1, z+\frac{1}{2}$; see Table 1 for more details].

A similar columnar arrangement is formed by the counter-ions. The alkyl chains are located tail-to-tail in $x$, but shifted by around $4 \AA\left[\mathrm{C} 1 \cdots \mathrm{C} 1^{\mathrm{v}}=4.09\right.$ (2) $\AA$; symmetry code: (v) $\left.-x+1, y,-z+\frac{1}{2}\right]$. The aromatic rings of contiguous $\mathrm{N}$-butylpyridinium cations in the column are alternating, with an angle of $\sim 38^{\circ}$ between pyridine rings $\left[\mathrm{C} 7-\mathrm{N} 1-\mathrm{N} 1^{\mathrm{iv}}-\right.$ $\mathrm{C}^{\text {iv }}=38.2(3)^{\circ}$; see Fig. 2].

The different packing arrangements of the undecachlorocarbadodecaborate were studied by the analysis of a set of five similar compounds (Fig. 3 and Table 1). One major difference observed in the crystal packing (Fig. 3) is related to the intermolecular $\mathrm{C}-\mathrm{H} \cdots \mathrm{Cl}$ interactions between pairs of undecachlorocarbadodecaborate units. It was found that where the counter-ion is large, the carboranes associate in pairs to form column of dimers [Fig. 3; structures $A, B$ (present structure) and $C$, but there is a variation in the torsion angle defined by the two C..Ce vectors in the dimers, and also in that relating the centroids of the undecachlorocarbadodecaborate into the double chain; the torsion angle changes as a result of the approach between dimers (shortest distance $\mathrm{H} \cdots \mathrm{Cl}$ ). In the case of structure $C$, the first of these angles has increased to $76^{\circ}$ which leads to the separations between chains being controlled by the $\mathrm{H} \cdots \mathrm{Cl}$ distance (being shorter and equal). In contrast, for the smaller cations (Fig. 3; structures $D$, $E$ and $F$ ), single strands are formed, where there is a bifurcated interaction of the $\mathrm{H}$ atom with two $\mathrm{Cl}$ atoms of the adjacent undecachlorocarbadodecaborate unit. Adjacent channels can be coplanar or displaced. The overall packing is therefore seen to be a balance between the various interactions available along with the relative sizes and shapes of the components.

\section{Experimental}

The title compound was obtained by a metathesis reaction between caesium undecachlorocarbadodecaborate and $N$-butylpyridinium chloride in a dichloromethane-acetone mixture under aerobic conditions. $N$-Butylpyridinium chloride $(100 \mathrm{mg})$ was dissolved in dichloromethane $(20 \mathrm{ml})$. An equimolar quantity of caesium undecachlorocarbadodecaborate was dissolved in a dichloromethaneacetone mixture $(1: 1 \mathrm{v} / \mathrm{v}, 10 \mathrm{ml})$ and the resulting solution was added to the $N$-butylpyridinium chloride solution. The formation of a white precipitate was evident almost immediately. The reaction mixture was stirred at room temperature for $30 \mathrm{~min}$. Subsequently, the solution was filtered through a Celite plug to remove the $\mathrm{CsCl}$ precipitate. The mother liquor was pumped off to dryness, the oily residue was redissolved in a small amount of dry dichloromethane and colourless scale-like crystals of (I) were grown by slow vapour diffusion of hexane into a dichloromethane solution at $243 \mathrm{~K}$.

\section{Crystal data}

$\mathrm{C}_{9} \mathrm{H}_{14} \mathrm{~N}^{+} \cdot \mathrm{CHB}_{11} \mathrm{Cl}_{11}$

$M_{r}=657.22$

Monoclinic, $C 2 / c$

$a=32.929(3) \mathrm{A}$

$b=10.2492(6) \AA$

$c=17.6340(19) \AA$

$\beta=111.100(12)^{\circ}$

\section{Data collection}

Oxford Gemini E CCD areadetector diffractometer

Absorption correction: multi-scan

(CrysAlis PRO; Oxford

Diffraction, 2009)

$T_{\min }=0.203, T_{\max }=1.000$

Refinement

$R\left[F^{2}>2 \sigma\left(F^{2}\right)\right]=0.071$

$w R\left(F^{2}\right)=0.233$

$S=1.05$

5577 reflections

302 parameters

Methyl and methylene $\mathrm{H}$ atoms were idealized at $\mathrm{C}-\mathrm{H}=0.96$ and $0.97 \AA$, respectively, and allowed to ride. Aromatic ring $\mathrm{H}$ atoms were idealized at $\mathrm{C}-\mathrm{H}=0.93 \AA$. $\mathrm{H}$-atom displacement parameters were taken as $U_{\text {iso }}(\mathrm{H})=1.5 U_{\text {iso }}(\mathrm{C})$ for methyl groups or $1.2 U_{\text {iso }}(\mathrm{C})$ otherwise. Atom $\mathrm{H} 10$ of the undecachlorocarbadodecaborate anion was located in a difference Fourier map and refined freely.

Data collection: CrysAlis PRO (Oxford Diffraction, 2009); cell refinement: CrysAlis PRO; data reduction: CrysAlis PRO; program(s) used to solve structure: SHELXS86 (Sheldrick, 2008); program(s) used to refine structure: SHELXL97 (Sheldrick, 2008); molecular graphics: ORTEP-3 (Farrugia, 1997); software used to prepare material for publication: Win GX (Farrugia, 1999).

Support for this research via Award PRF 44692.01-GB from the American Chemical Society and Cottrell College Award CC6755 from Research Corporation is gratefully acknowledged. Professor Oleg Ozerov and Weixing Gu of Texas A\&M University are gratefully acknowledged for providing the caesium perchlorinated carborane salt. John Holbrey's group of Queen's University in Belfast is acknowledged for donation of the stock alkylpyridinium halide salts. We thank Miss Bushra Amreen for organizational help with this project at Ithaca College. Thanks are also expressed to Ricardo Baggio, and to ANPCyT (grant No. PME-2006-01113).

Supplementary data for this paper are available from the IUCr electronic archives (Reference: SF3157). Services for accessing these data are described at the back of the journal.

\section{References}

Berg, J. A. van den \& Seddon, K. R. (2003). Cryst. Growth Des. 3, 643-661. Dymon, J., Wibby, R., Kleingardner, J., Tanski, J. M., Guzei, I. A., Holbrey, J. D. \& Larsen, A. S. (2008). Dalton Trans. pp. 2999-3006.

Farrugia, L. J. (1997). J. Appl. Cryst. 30, 565.

Farrugia, L. J. (1999). J. Appl. Cryst. 32, 837-838.

Gu, W., McCulloch, B. J., Reibenspies, J. H. \& Ozerov, O. V. (2010). Chem. Commun. pp. 2820-2822. 


\section{organic compounds}

Table 1

Structural comparison of different undecachlorocarbadodecaborate salt compounds.

Superscripts i, ii, iii, iv and v refer to different symmetry operations according to each structure, $x$ refers to the corresponding C number and $C e$ denotes the centroid of the undecachlorocarbadodecaborate anion; ODCB is $o$-dichlorobenzene.

\begin{tabular}{|c|c|c|c|c|c|}
\hline Counter-ion & $\mathrm{C}_{x} \cdots C e \cdots C e^{\mathrm{v}} \cdots \mathrm{C}_{x}^{\mathrm{v}}\left({ }^{\circ}\right)$ & $C e^{\mathrm{i}} \cdots C e^{\mathrm{ii}} \cdots C e^{\mathrm{iii}} \cdots C e^{\mathrm{iv}}\left(^{\circ}\right)$ & $\mathrm{Cl} \cdots \mathrm{H}(\AA) \dagger$ & Distance between chains $(\AA) \neq$ & Distance between chains $(\AA) \S$ \\
\hline$A \mathrm{Me}_{3} \mathrm{Si}-\mathrm{H}-\mathrm{SiMe}_{3}$ & 0 & 180 & 3.04 & 3.73 & $3.79,3.83$ \\
\hline$B \mathrm{C}_{4} \mathrm{H}_{9}-\mathrm{C}_{5} \mathrm{H}_{5} \mathrm{~N}$ & 33 & 176 & 2.94 & $3.56,4.43$ & $3.76,3.94$ \\
\hline$C\left(\mathrm{C}_{3} \mathrm{H}_{7}\right)_{3}-\mathrm{Si}-(\mathrm{ODCB})$ & 76 & 167 & 2.92 & 2.92 & $3.78,4.08$ \\
\hline$D \mathrm{Me}-\mathrm{Cl}-\mathrm{Me}$ & 0 & 116 & 2.97 & $3.52,4.06$ & 3.45 \\
\hline$E \mathrm{Et}-\mathrm{Cl}-\mathrm{Et}$ & 89 & 152 & $2.85,3.21$ & $3.58,3.67$ & $3.58,3.67$ \\
\hline$F\left[\mathrm{H}(\mathrm{MeOH})_{3}\right]^{+}$ & 107 & 147 & $2.96,3.10$ & 3.36 & $3.46,3.58$ \\
\hline
\end{tabular}

$\uparrow$ The closest $\mathrm{H} \cdots \mathrm{Cl}$ distance forming dimers or not, depending on the compound. $\ddagger$ The minimum $\mathrm{Cl} \cdots \mathrm{Cl}$ distance between undecachlorocarbadodecaborate anions along the

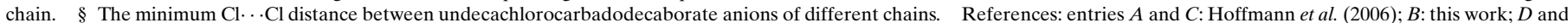
E: Stoyanov et al. (2010); F: Stoyanov et al. (2008).

Hoffmann, S. P., Kato, T., Tham, F. S. \& Reed, C. A. (2006). Chem. Commun. pp. 767-769.

Larsen, A. S., Holbrey, J. D., Tham, F. S. \& Reed, C. A. (2000). J. Am. Chem. Soc. 122, 7264-7272.

Lu, Y.-X., Zou, J.-W., Wang, Y.-H. \& Yu, Q.-S. (2007). Int. J. Quantum Chem. 107, 1479-1486.

Metrangolo, P., Meyer, F., Pilati, T., Resnati, G. \& Terraneo, G. (2008). Angew. Chem. Int. Ed. 47, 6114-6127.
Oxford Diffraction (2009). CrysAlis CCD and CrysAlis RED. Oxford Diffraction Ltd, Yarnton, Oxfordshire, England.

Reed, C. A. (2010). Acc. Chem. Res. 43, 121-128.

Sheldrick, G. M. (2008). Acta Cryst. A64, 112-122.

Stoyanov, E. S., Stoyanova, I. V., Tham, F. S. \& Reed, C. A. (2008). J. Am. Chem. Soc. 130, 12128-12138.

Stoyanov, E. S. Stoyanova, I. V., Tham, F. S. \& Reed, C. A. (2010). J. Am. Chem. Soc. 132, 4062-4063. 